\title{
Bilateral Ultrasound-Guided Rectus Sheath Block for Anesthesia of Midline Laparotomy
}

\author{
Orta Hat Laparotomisi Anestezisi İçin \\ Ultrasonografi Eşliğinde Bilateral Rektus \\ Kılıf Bloğu
}

\begin{abstract}
Tracheoesophageal fistula (TEF) may develop in 5\% to 15\% of patients with esophageal cancer. This may cause complications such as aspiration, bleeding, perforation, migration and pneumonia during general anesthesia and care should be taken in anesthesia management. In this case report, the perianesthetic management of bilateral rectus sheet block (RSB) application as the primary anesthesia technique for midline laparotomy in a patient with malignant TEF and pneumonia is discussed.
\end{abstract}

Keywords: Rectus sheath block, ultrasonography, anesthesia, perioperative analgesia, midline laparotomy

öz

Özofagus kanseri olan hastaların \%5 ila \%15'inde trakeoözofageal fistül (TEF) gelişebilir. Bu da genel anestezi sırasında aspirasyon, kanama, perforasyon, migrasyon ve pnömoni gibi komplikasyonlara sebep olabilir ve anestezi yönetiminde dikkatli olunmalıdır. Bu olgu sunumunda, malign TEF ve pnömonisi olan hastaya orta hat laparotomisi için primer anestezi tekniği olarak bilateral rektus kılıf bloğu (RSB) uygulamasının perianestetik yönetimi tartışılmaktadır.

Anahtar kelimeler: Rektus kılıf bloğu, ultrasonografi, anestezi, perioperatif analjezi, orta hat laparotomi
Received/Geliş: 23 June 2021 Accepted/Kabul: 14 September 2021 Publication date: 27 September 2021

Cite as: Ersoy Z, Ensarioglu M, Araz C. Bilateral ultrasound-guided rectus sheath block for anesthesia of midline laparotomy. JARSS 2021;29(4):283-6.

Zeynep Ersoy

Başkent Üniversitesi Tıp Fakültesi, Anesteziyoloji Anabilim Dalı, Ankara, Türkiye

zeynepsener2003@yahoo.com ORCID: 0000-0003-0767-1088

M. Ensarioglu 0000-0003-2759-9714 C. Araz 0000-0002-4927-6660 Başkent Üniversitesi Tıp Fakültesi, Anesteziyoloji Anabilim Dalı, Ankara, Türkiye

\section{INTRODUCTION}

Malignant tracheoesophageal fistula (TEF) develops in $5 \%$ to $15 \%$ of adults with esophageal cancer ${ }^{(1)}$. Positive pressure ventilation in TEF patients insufflates the esophagus and stomach, decreases pulmonary compliance, and increases the risk of aspiration due to intestinal distention. For these reasons, some anesthesiologists prefer inhalation induction or awake intubation to maintain spontaneous ventilation for these reasons. Positive pressure ventilation, on the other hand, is easy to perform when the lungs are separated and ventilation through the fistula is prevented. When positive pressure ventilation is required, a gastrostomy tube, commonly used to feed patients with esophageal cancer, can help prevent gastric distention. In patients with severe pulmonary disease undergoing major surgery, one-lung ventilation may be incompatible with normal oxygenation and ventilation ${ }^{(2)}$.

Rectus sheath block (RSB) can reduce the stress response and inflammation and facilitate the use of anesthetics. RSB, which blocks the modulation of the sensory nerve on the anterior abdominal wall, is commonly used in abdominal and pelvic surgery for anesthesia and postoperative analgesia (3). We present here a case of an intestinal exploration and placement of a Witzel jejunostomy for a malignant TEF was performed in a American Society of Anesthesiologists (ASA) class IV patient under realtime ultrasound-guided RSB without general anesthesia or central neuroaxial blockade. 


\section{CASE REPORT}

A 65-year-old woman with a body mass index of 16 $\mathrm{kg} \mathrm{m}^{-2}$ underwent transhiatal esophagectomy 4 years ago for esophageal cancer. Because of tomographically confirmed TEF and pneumonia, a palliative feeding jejunostomy was planned (Figure 1). Laboratory values were normal. This ASA IV patient with left ventricular diastolic dysfunction had a Metabolic Equivalent Test Score (METs) of 2 and a Glasgow coma score of 15 . She had pneumonia, but arterial blood gases sample did not show hypoxemia or hypercarbia and was receiving antibiotherapy to treat the pneumonia and low molecular weight heparin (LMWH) for prophylaxis of deep vein thrombosis (DVT).

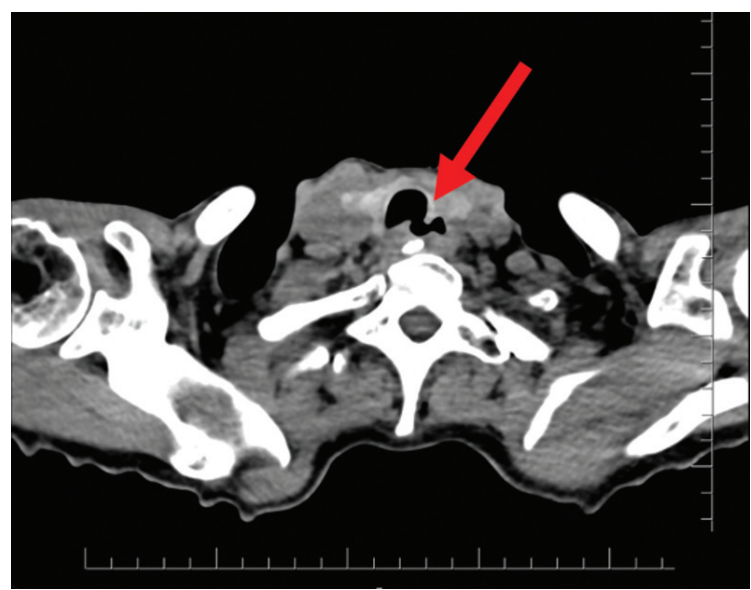

Figure 1. TEF image of the patient in computed tomography

Following patients informed consent, it was decided to perform the surgery under bilateral RSB with mild sedation to reduce the risk of complications. Neuraxial blockade was not prefered as its risk of severe hemodynamic fluctuations and hypotension, which might be harmful to the patient. After vascular access, standard intraoperative monitoring included electrocardiography, pulse oximetry, and noninvasive blood pressure monitoring. Nasal oxygen delivery was started at a rate of $3 \mathrm{~L} \mathrm{~min}^{-1}$. The patient was first sedated with $0.04 \mathrm{mg} \mathrm{kg}^{-1}$ midazolam IV. Following the scrubing of the skin RSB was performed bilaterally with an isolated 22G, $80 \mathrm{~mm}$ (Stimuplex ${ }^{\circledR}$, B. Braun, Melsungen, Germany) needle in the plane under real-time ultrasound guidance (HFL38x/4.5-13 $\mathrm{MHz}$ Linear Array Transducer; General Electric,
LOGICe, Fairfield, Connecticut, USA). Fifteen $\mathrm{mL}$ of $0.5 \%$ bupivacaine and $5 \mathrm{~mL}$ of prilocaine were injected into the space between the rectus abdominis muscle and the posterior rectus sheath on each side. The patient was tested for touch and pain sensations with an ice battery, cold and warm stimuli, and a pinprick test at 5-minute intervals. Surgery began after approximately 20 minutes.

At the beginning of surgery, $1 \mu \mathrm{g} \mathrm{kg}^{-1}$ fentanyl IV was administered for sedation. The patient did not complain of pain. A $10 \mathrm{~cm}$ incision was made for exploration of difficult surgery. We administered $0.15 \mu \mathrm{g} \mathrm{kg}^{-1}$ ketamine to prevent spontaneous leg movement. The bowel was explored before the jejunostomy procedure. A Witzel jejunostomy catheter was placed (Figure 2), then fascial closure was performed, primarily with interrupted 1-0 prolene sutures, followed by subcutaneous and subcuticular closure.

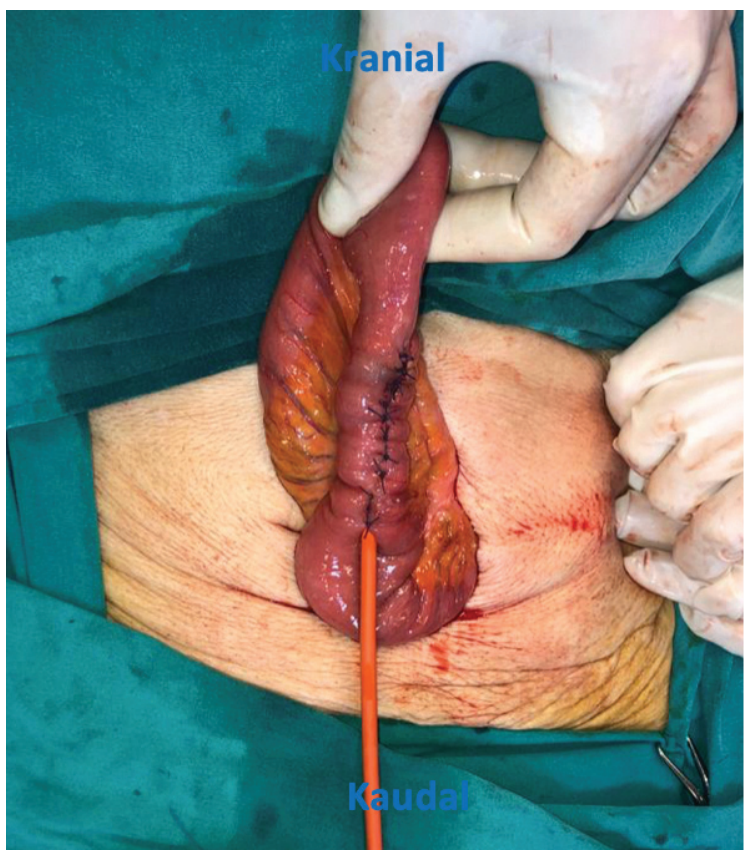

Figure 2. Placement of Witzel jejunostomy catheter in a patient with. TEF

The surgery was continued 90 minutes after blockade and proceeded without complications. Throughout the procedure, the patient was pain-free, relaxed, and hemodynamically stable, with all vital signs within $10 \%$ of baseline. No additional medications were required during the 90 minutes surgery. The patient was monitored closely in the recovery room. 
She did not require analgesics and was discharged back to the ward after 30 minutes.

The postoperative Visual Analog Scale (VAS) score was $3 / 10$. Pain scores at rest and on movement were also assessed 2, 4, 6, 12, 24 and 48 hours after surgery using a numerical rating scale (NRS) (0: no pain to 10: worst pain imaginable). The average pain score was 2 points (Table I). The patient was discharged on day 3 .

Table I. Pain, Numeric Rating Scale (NRS)

\begin{tabular}{lllllll}
\hline Hour & 2 & 4 & 6 & 12 & 24 & 48 \\
\hline NRS & 2 & 3 & 2 & 2 & 1 & 0 \\
\hline
\end{tabular}

\section{DISCUSSION}

In a patient with malignant TEF, who was scheduled for a paliative jejunostomy, we preferred bilateral RSB as an anesthetic technique to general anesthesia during laparotomy to avoid positive pressure ventilation, chronic aspiration and its complications (pneumonia, sepsis and hypoxemia).

Tracheoesophageal fistula is a rare condition that usually affects adults and is caused by trauma, ingestion of corrosive substances, foreign bodies, inflammatory processes or cancer. Problems with oxygenation and/or ventilation can occur when the endotracheal tube is placed in or over the fistula, resulting in gastric dilatation, atelectasis, or pulmonary aspiration. Unless the fistula is treated to prevent ventilation of the TEF, standard anesthetic management includes awake tracheal intubation, avoidance of muscle relaxants, and positive pressure ventilation. Bronchial blockers can be inserted into the TEF under fiberoptic guidance to prevent ventilation of the esophagus and stomach and to facilitate surgical identification of the fistula ${ }^{(4)}$. For all these reasons, we avoided general anesthesia in this patient.

We did not prefer the method of central neuraxial block, which may cause hemodynamic changes in a cachectic and frail patient of ASA IV class. RSB does not cause the physiological sympathectomy that occurs with central neuraxial block, thus avoiding hemodynamic instability that is common with such block. At the same time, because this patient had pneumonia, we decided against central block to avoid the possibility of bacteremia and DVT. In addition, unlike neuraxial blockade, RSB can be used in the presence of relative coagulopathy and recent use of antiplatelet agents or anticoagulants. This could lead to significant therapeutic benefits lowering risks of deep vein thrombosis, pulmonary embolism, atelectasis, pulmonary infection, and prevent motor weakness ${ }^{(3)}$. One study reported that a combination of IV dexmetedomidine and RSB may be a viable alternative to epidural anesthesia in patients with a midline incision ${ }^{(5)}$.

Schleich ${ }^{(6)}$ was the first to define RSB as a safer technique for anterior abdominal wall surgery in adults. The ventral branches of the spinal nerve roots $\mathrm{T}_{7}-\mathrm{T}_{11}$ innervate the central part of the anterior abdominal wall. They lie between the rectus abdominis muscle and the posterior rectus sheath and meet the rectus muscle near the midline. Anatomically as the tendon insertions of the rectus muscle are not fused to the posterior rectus sheath, the local anesthetic spreads cephalocaudally throughout this compartment with a single injection ${ }^{(7)}$.

The rectus sheath block technique is becoming increasingly popular for incisions in the midline from the xyphoid to the symphysis pubis ${ }^{\left({ }^{8}\right)}$. Previous studies on RSB mainly focused on lower abdominal procedures. In postoperative analgesia of abdominal procedures such as laparoscopic cholecystectomy and gynecologic oncology surgery, RSB was performed with minimal problems and a high success rate ${ }^{(9,10)}$. In another study, the importance of transversus abdominis plane block (TAPB) and RSB was highlighted. With the advancement of ultrasound technology, many regional anesthetic blocks can now be safely and visibly performed, and it is regularly used for clinical anesthesia and postoperative analgesia. TAPB and RSB have antiinflammatory properties and can reduce nonnociceptive and nociceptive stimuli (11). When regional anesthetic techniques such as TAP+RS block are used, several studies have shown that opioid consumption is reduced postoperatively ${ }^{(12)}$. Li et al. (13) pointed out that patients who received TAP +RS block anesthesia had more stable intraoperative hemodynamics and required less vasoactive drugs. 
The TAP+RS block is safe for patients with end-stage renal disease because it does not affect sympathetic nerves. Wilkinson et al. (14) have demonstrated the analgesic efficacy, safety, and cost-effectiveness of the block.

Rectus sheath block provides dense analgesia with a shorter duration than TAP block ${ }^{(15)}$. Therefore, we preferred the RSB over the TAP block in our patient.

Rectus sheath block may be a useful technique for surgical anesthesia in adult patients who do not allow general anesthesia or neuraxial block for medical reasons. To our knowledge, a case has been published by Quek et al. ${ }^{(3)}$ in which the effects of RSB on surgical pain, hemodynamic response, and postoperative incisional pain were studied. However, the number of studies using this block for different surgical procedures is limited.

We concluded that superficial RSB may be beneficial for surgical field anesthesia and postoperative pain control in patients with various comorbid conditions in whom general anesthesia is risky and who require abdominal surgery.

\section{CONCLUSION}

Rectus sheath block is actually used for analgesic purposes and also for anesthesia in certain and selected patients. RSB is acceptable as an anesthetic technique in high-risk patients with compromised cardiovascular and physiologic systems.

\section{Conflict of Interest: None \\ Informed Consent: Informed consent was obtained}

\section{REFERENCES}

1. Deshpande G, Samarasam I, Banerjee S, Gnanamuthu RB, Chandran S, Mathew G. Benign esophagorespiratory fistula: a case series and a novel technique of definitive management. Dis Esophagus. 2013;26:141-7. https://doi:10.1111/j.1442-2050.2012.01347.x

2. Ghaffaripour S, Souki FG, Martinez-Lu K. Anesthetic Approach for Endoscopic Repair of Acquired Tracheoesophageal Fistula. Seminars in Cardiothoracic and Vascular Anesthesia. 2017;21:357-9. https://doi.org/10.1177/1089253217706165

3. Quek KHY, Phua DSK. Bilateral rectus sheath blocks as the single anaesthetic technique for an open infraumbilical hernia repair. Singapore Med J.
2014;55:39-41.

https://doi.org/10.11622/smedj.2014042

4. Robins B, Das AK. Anesthetic Management of Acquired Tracheoesophageal Fistula: A Brief Report. Anesthesia \& Analgesia. 2001;93:903-5. https://doi.org/10.1097/00000539-200110000-00020

5. Li Y, Jiang X, Wang J, et al. Intravenous Dexmedetomidine Combined with Ultrasound-Guided Rectus Sheath Block for Open Gastrectomy: a Prospective Randomized Trial. Gastrointest Surg. 2019;24:1290-7. https://doi.org/10.1007/s11605-019-04249-2

6. Schleich DL. Schmerzlose Operationen. 4th ed. Berlin: Springer Verlag. 1899;240-58.

7. Abrahams MS, Horn JL, Noles LM, Aziz MF. EvidenceBased Medicine: Ultrasound Guidance for Truncal Block. Reg Anaesth Pain Med. 2010;35:36-42. https://doi.org/10.1097/AAP.0b013e3181d32841

8. Willschke $H$, Bösenberg $A$, Marhofer $P$, et al. Ultrasonography-guided rectus sheath block in paediatric anaesthesia-a new approach to an old technique. Br J Anaesth. 2006;97:244-9. https://doi:10.1093/bja/ael143

9. Lui MW, Li TKT, Lui F, Ong CYT. A randomised, controlled trial of rectus sheath bupivacaine and intrathecal bupivacaine, without or with intrathecal morphine, vs. intrathecal bupivacaine and morphine after caesarean section. Anaesthesia. 2017;72:1225-9. https://doi.org/10.1111/anae.13998

10. Bakshi SG, Mapari A, Shylasree TS. REctus Sheath block for post- operative analgesia in gynecological ONcology Surgery (RESONS): a randomized-controlled trial. Can J Anaesth. 2016;63:1335-44. https://doi.org/10.1007/s12630-016-0732-9

11. Kuchálik J, Magnuson A, Tina E, Gupta A. Does local infiltration analgesia reduce peri-operative inflammation following total hip arthroplasty? A randomized, double-blind study. BMC Anesthesiol. 2017;17:63. https://doi.org/10.1186/s12871-017-0354-y

12. Xia J, Paul Olson TJ, Tritt S, Liu Y, Rosen SA. Comparison of preoperative versus postoperative transversus abdominis plane and rectus sheath block in patients undergoing minimally invasive colorectal surgery. Colorectal Dis. 2019;22:569-80. https://doi.org/10.1111/codi.14910

13. Li J, Guo W, Zhao W, et al. Ultrasound-Guided Unilateral Transversus Abdominis Plane Combined with Rectus Sheath Block versus Subarachnoid Anesthesia in Patients Undergoing Peritoneal Dialysis Catheter Surgery: A Randomized Prospective Controlled Trial. J Pain Res. 2020;13:2279-87. https://doi.org/ 10.2147/JPR.S264255

14. Wilkinson KM, Krige A, Brearley SG, et al. Thoracic epidural analgesia versus Rectus SheathCatheters for open midline incisions in major abdominal surgery within an enhanced recovery programme (TERSC): study protocol for a randomised controlled trial. Trials. 2014;15:400.

http://www.trialsjournal.com/content/15/1/400

15. Webster K. Ultrasound guided rectus sheath blockanalgesia for abdominal surgery. Update in Anesthesia 2010;26:12-7.

https://e-safe-anaesthesia.org. 